\title{
Internet of Things (IoT) Based Temperature and Humidity Monitoring System in the Chemical Laboratory of the Samarinda Industry Standardization and Research Center
}

\author{
Muhammad Awaludin \\ STMIK Widya Cipta Dharma, \\ Samarinda, 75123, Indonesia \\ mhmmdawhal@gmail.com \\ *Corresponding author
}

\author{
Andi Yusika Rangan \\ STMIK Widya Cipta Dharma, \\ Samarinda, 75123, Indonesia \\ andi@wicida.ac.id
}

\author{
Amelia Yusnita \\ STMIK Widya Cipta Dharma, \\ Samarinda, 75123, Indonesia \\ amelia@wicida.ac.id
}

Received: 2021-03-01; Revised: 2021-06-27; Accepted: 2021-07-31; Published: 2021-09-01

\begin{abstract}
Temperature and humidity are important things in a chemical laboratory. By utilizing the internet, operators can remotely monitor laboratory temperatures and humidity with the Internet of Things (IoT) system. The Internet of Things (IoT) system can make it easier for operators to monitor temperature and humidity in chemical laboratories wherever and whenever. DHT11 sensor which functions as a temperature and humidity detector, NodeMCU ESP8266 microcontroller which functions as a data processor so that the DHT11 sensor detection results can be displayed on the monitoring website so that operators can see directly the results of temperature and humidity measurements at the chemical laboratory. This research was conducted at the Samarinda Industrial Research and Standardization Center. Data collection methods used are literature study, interviews, and observations. While the system development method used is prototype. As well as the supporting software used by the Arduino Integrated Development Environment, XAMPP, and Sublime.
\end{abstract}

Keywords-Monitoring, Temperature, Humidity, NodeMCU ESP8266, DHT11 Sensor, Internet of Things

\section{INTRODUCTION}

A chemical laboratory is a special room equipped with the necessary tools and facilities so that it can be used for conducting experiments, scientific research, measurements or scientific training. Air temperature and humidity are important in chemical laboratories, because they greatly affect substances or materials that are sensitive to changes in temperature and humidity which can react at one time (April 2016).

Changes in temperature and humidity must be easily and precisely monitored so that the laboratory room conditions can be declared safe. Monitoring of temperature and humidity in chemical laboratories has been done manually using a thermometer or hygrometer, operators have to go out and out of the chemical laboratory repeatedly to collect air temperature and humidity data.

Based on the above, research was carried out at the chemical laboratory at the Samarinda Industrial Research and Standardization Center (Baristand Industri Samarinda) so that temperature and humidity monitoring can be monitored remotely in real time through an interface without having to go out and about in the chemical laboratory by utilizing technology temperature and humidity sensor. In this research, a tool will be made that can monitor air temperature and humidity in an IoT-based chemical laboratory (Irfan, 2016).

\section{LITERATURE REVIEW}

\section{A. System}

According to Susanto (2013) a system is a collection (group) of subsystems / parts / components of any physical or non-physical which are interconnected with each other and work together harmoniously to achieve a specific goal.

According to Gaol (2013), the system is the relationship of one unit to other units that are interconnected with each other and which cannot be separated and lead to a single unit in order to achieve predetermined goals. If one unit is jammed or disturbed, other units will also be disturbed to reach the stated destination.

\section{B. Monitoring}

According to Sutabri (2012) Monitoring is defined as a step to assess whether the activities carried out are in accordance with the plan, identify problems that arise so that they can be immediately resolved, assess whether the work patterns and management used are appropriate to achieve goals, find out the relationship between activities and objectives. to get a measure of progress.

According to Aviana (2012) Monitoring is a very important process in organizational activities that can 
determine whether or not an organizational goal is implemented. The purpose of monitoring is to ensure that the main tasks of the organization can run according to a predetermined plan.

\section{Temperature}

According to Hidayati (2011), the temperature in Picture 1 is a quantity that states the degree of heat and coldness of an object and the tool used to measure temperature is a thermometer. In everyday life people tend to use the sense of touch to measure temperature.

According to Sunardi and Siti (2013), temperature can be defined as a measure of the degree of heat or coldness of an object. To measure the temperature of an object, a device called a thermometer is used. Thermometer is a tool used to measure the temperature of an object or system quantitatively.

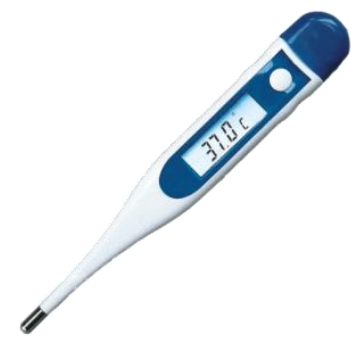

Picture 1. Temperature

\section{Internet of Things (IoT)}

According to Hardyanto (2017) Internet of Things can be defined as the ability of various devices to connect and exchange data through the internet network. IoT is a technology that allows control, communication, collaboration with various hardware, data via the internet network. So it can be said that the Internet of Things (IoT) is when we connect things (things) that are not operated by humans to the internet.

According to Burange and Misalkar (2015) Internet of Things (IoT) is a structure in which objects, people are provided with an exclusive identity and the ability to move data through the network without requiring two directions between humans, namely source to destination or human to computer interaction.

\section{E. Chemistry laboratory}

According to Amanah (2011) the laboratory is one of the places for the development of science through various research and experiments, in research or experimental activities, of course, using various types of tools and chemicals to support their activities and several other supporting facilities such as water, gas, electricity and cupboards. Acid, of course, tools, chemicals and laboratory facilities and their activities have the potential to cause an accident. Potential hazards that occur in chemical laboratories include when taking reagents from the fume hood, potential hazards that occur such as poisoning, shortness of breath, eye irritation, skin irritation, and burns. Then when filling the burette there are potential hazards such as injury, eye irritation, and ingestion of chemicals. The use of ovens and stoves with existing potential hazards such as exposure to heat, fire, use of measuring cups that are lumpy results in scratches. Taking reagents from a cupboard or storage area for chemicals is a potential hazard that can occur, including dizziness, nausea, sore throat, eye irritation and shortness of breath.

\section{F. ESP8266 NodeMCU microcontroller}

NodeMCU in Picture 2 is an IoT platform that is open source. The hardware consists of the ESP8266 System On Chip from the ESP8266 made by Ekspresif System, as well as the firmware used, which uses the Lua scripting programming language. The term NodeMCU by default actually refers to the firmware used instead of the development kit hardware. (Ekojono et al, 2018) The development of this kit is based on the ESP8266 module, which integrates GPIO, PWM (Pulse Width Modulation), IIC, 1-Wire, and ADC (Analog to Digital Converter) all on one board. The uniqueness of NodeMCU is its very small board, which is $4.83 \mathrm{~cm}$ long, $2.54 \mathrm{~cm}$ wide, and weighs 7 grams. But despite its small size, this board is equipped with Wi-Fi features and open source firmware. The use of NodeMCU is more profitable in terms of cost and space efficiency, because NodeMCU is small in size, more practical and the price is much cheaper than the Arduino Uno. Arduino Uno itself is one type of microcontroller that is in great demand and has the same $\mathrm{C}++$ programming language as NodeMCU, but Arduino Uno does not have a Wi-Fi module and is not based on IoT (Internet of Things). To be able to use the Arduino Uno Wi-Fi requires an additional device in the form of a $\mathrm{Wi}-\mathrm{Fi}$ shield. but Arduino Uno does not have a Wi-Fi module and is not based on IoT (Internet of Things). To be able to use the Arduino Uno $\mathrm{Wi}-\mathrm{Fi}$ requires an additional device in the form of a Wi-Fi shield. but Arduino Uno does not have a Wi-Fi module and is not based on IoT (Internet of Things). To be able to use the Arduino Uno $\mathrm{Wi}$-Fi requires an additional device in the form of a $\mathrm{Wi}$ Fi shield.

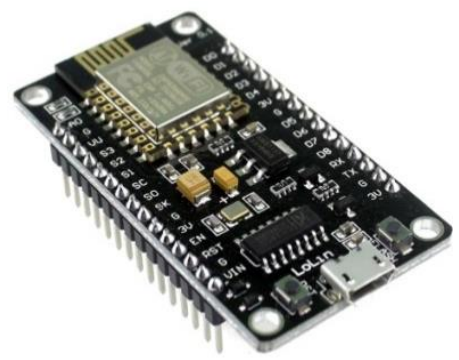

Picture 2. NodeMCU Board

Specifications owned by NodeMCU.

1. Board This is based on the ESP8266 serial wifi SoC (Single on Chip) with onboard USB to TTL, the wireless used is IEE $802.11 \mathrm{~b} / \mathrm{g} / \mathrm{n}$.

2. 2 tantalumcapsitir 100 micro farad and 10 micro farad. 
3. 3.3v LDO regulator.

4. Blue $L E D$ as an indicator.

5. Cp2102 USB to UART Bridge.

6. Reset button, USB port and flash button.

7. There are 9 GPIOs in which there are 3 PWM pins, $1 \mathrm{x}$ ADC channel, and RX TX pins.

8. 3 ground pins.

9. S3 and S2 as GPIO pins

10. SI MOSI (Master Output Slave Input), namely the data path from the master and into the slave, SC $\mathrm{cmd} / \mathrm{sc}$

11. SO MISO (Master Slave Input) is the data path out of the slave and into the master.

12. SK which is the SCLK from master to slave which functions as a clock.

13. Pin Vin as a voltage charge.

14. Built in 32-bit MCU.

The ESP8266-12E NodeMCU circuit in Picture 3 is a brain and control system for a series of temperature and humidity monitoring tools using an online web based on ESP8266.

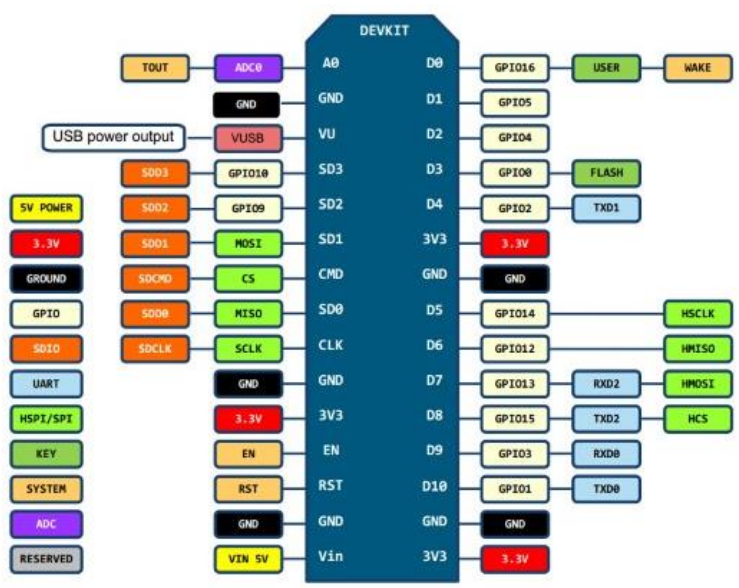

Picture 3. NodeMCU ESP8266 Pin Arrangement

From the picture above, you can see each of the ESP8266 NodeMCU pins.

1. RST: functions to reset the module.

2. ADC: Analog Digital Converter. Input voltage range $0-1 \mathrm{v}$, with digital value range 0-1024.

3. EN: Chip Enable, Active High.

4. IO16: GPIO16, can be used to build chipsets from deep sleep mode.

5. IO14: GPIO14; HSPI_CLK.

6. IO12: GPIO12; HSPI_MISO.

7. IO13: GPIO13; HSPI_MOSI; UART0_CTS.

8. VCC: $3.3 \mathrm{~V}$ (VDD) power supply.

9. CSO: Chip Selection.

10. MISO: Slave output, Main input.

11. IO9: GPIO9.

12. IO10 GBIO10.

13. MOSI: Main Output Slave Input.

14. SCLK: Clock.

15. GND: Ground.

16. IO15: GPIO15; MTDO; HSPICS; UART0_RTS.

17. IO2: GPIO2; UART1_TXD.
18. IO0: GPIO0.

19. IO4: GPIO4.

20. IO5: GPIO5.

RXD: UART0_RXD; GPIO3.TXD: UART0_TXD; GPIO1.

\section{G. DHT11}

The DHT11 sensor in Picture 4 is a sensor module that functions to sensing temperature and humidity objects that have an analog voltage output that can be further processed using a microcontroller. This sensor module is classified into a resistive element such as a temperature measuring device, for example, namely NTC. The advantages of this sensor module compared to other sensor modules are in terms of the quality of the reading of sensing data, which is more responsive, which has speed in terms of sensing temperature and humidity objects, and the data that is read is not easily interfered with. The DHT11 sensor generally features a fairly accurate temperature and humidity reading value calibration. The calibration data is stored in the OTP program memory which is also called the calibration coefficient

The DHT11 sensor has 2 versions, 4 pin version and 3 pin version. There is no difference in the characteristics of these 2 versions. In the 4 pin version,. Pin 1 is the source voltage, ranging from $3 \mathrm{~V}$ to $5 \mathrm{~V}$. Pin 2 is the output data. The 3rd pin is the NC pin (normally close) aka not used and the 4th pin is Ground. Whereas in the $3 \mathrm{leg}$ version, pin 1 is $\mathrm{VCC}$ between $3 \mathrm{~V}$ to $5 \mathrm{~V}$, pin 2 is the output data and pin 3 is Ground.
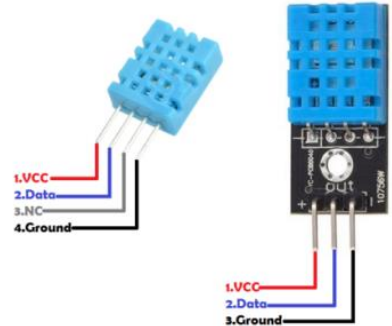

Picture 4. DHT11 Sensor Pin Arrangement

\section{H. Prototype Method}

The prototype method in Picture 5 used in this research is the prototype method, according to Roger S. Pressman, the stages of the prototype method are as follows:

1) Listening to Customers

At this stage, the system needs to be collected by listening to complaints from customers. To create a system that suits your needs, you must first know how the system is running and then find out what problems occur.

2) Designing and Making Prototypes

At this stage, the design and manufacture of a system prototype is carried out. Prototypes that are made are tailored to the system requirements that 
have been previously defined from customer or user complaints.

3) Trials

At this stage, the prototype of the system is tested by customers or users. Then do an evaluation of the deficiencies of the needs. Development then returned to listening to complaints from customers to improve the existing prototype.

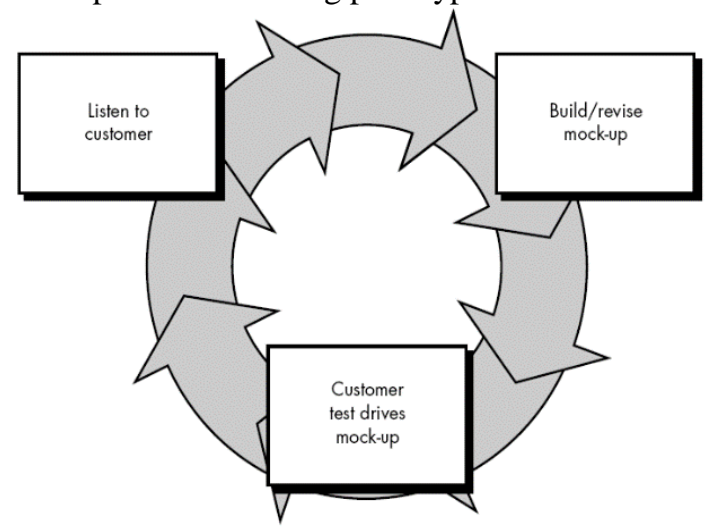

Picture 5. Prototype Model

\section{White-Box Testing}

White-box testing is done to test existing procedures. By looking into the module to examine the existing program code and analyze whether there is an error or not if the module produces output that is not in accordance with the process being carried out, the program lines, variables, and parameters involved in that unit will be checked. One by one and repaired then recompiled (Prasetyo, 2018).

\section{RESEARCH METHODS}

The block diagram in Picture 6, explains the design of a temperature and humidity monitoring system design in a chemical laboratory. The DHT11 sensor measures the temperature and humidity of the air in the chemical laboratory, then the NodeMCU ESP8266 microcontroller processes the sensor data that has been obtained from the DHT11 sensor which is then displayed on the LCD (Liquid Crystal Display), there is an ESP8266 connected to the NodeMCU which functions for connection to a $\mathrm{Wi}-\mathrm{Fi}$ network where DHT11 sensor data is sent or stored to the database so that the sensor data can be displayed remotely in real time using the Monitoring Website, and there is a relay that functions to connect and cut off the electric current on the fan (Saputro, 2017).

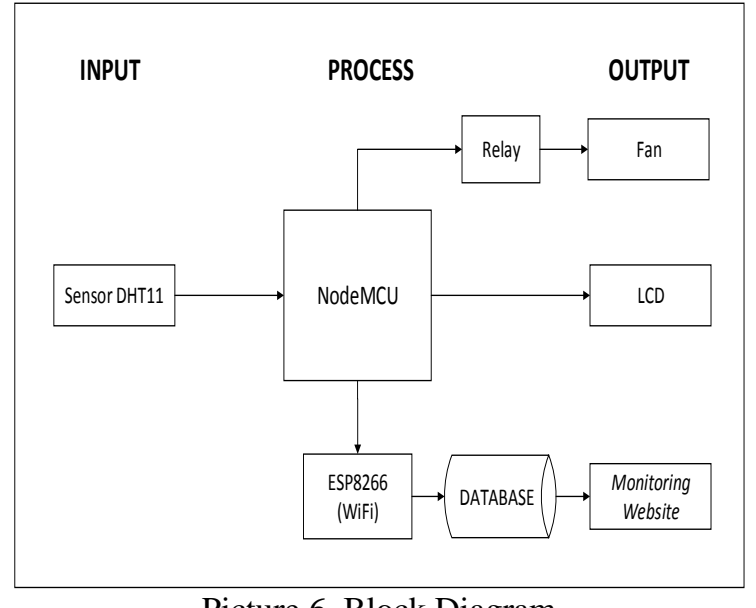

Picture 6. Block Diagram

Picture 7 is a network architecture image consisting of several components.

1. ESP8266 (WiFi): this tool functions to send sensor data obtained from the DHT11 sensor, sensor data is sent in the form of an HTTP request to the server via the HTTP protocol.

2. Access Point: used to connect the ESP8266 to the internet.

3. Server: functions to receive and process data from the sensor results sent by the ESP8266 via the HTTP protocol.

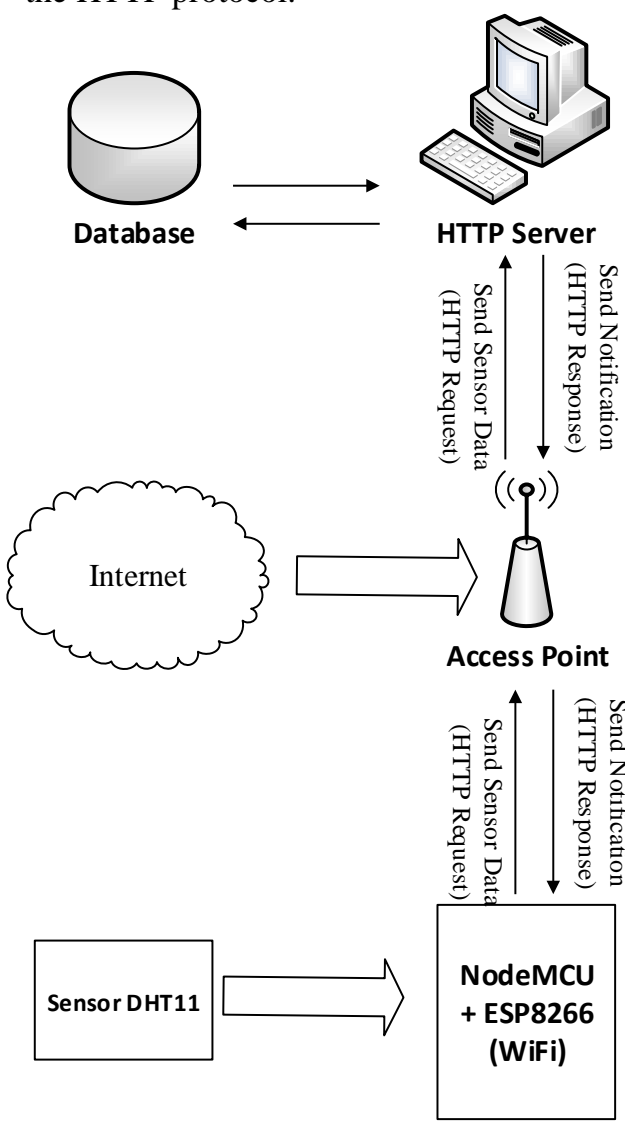

Picture 7. Network Architecture

The system flowchart in Picture 8 explains that when the temperature and humidity monitoring tool is 
turned on, the first thing to do is measure the temperature and humidity. The measurement results are displayed in the form of output that is displayed on the LCD (Liquid Crystal Display) and the temperature and humidity monitoring website that has been made. If the temperature exceeds 25 degrees Celsius, the automatic cooling control system will be $\mathrm{ON}$.

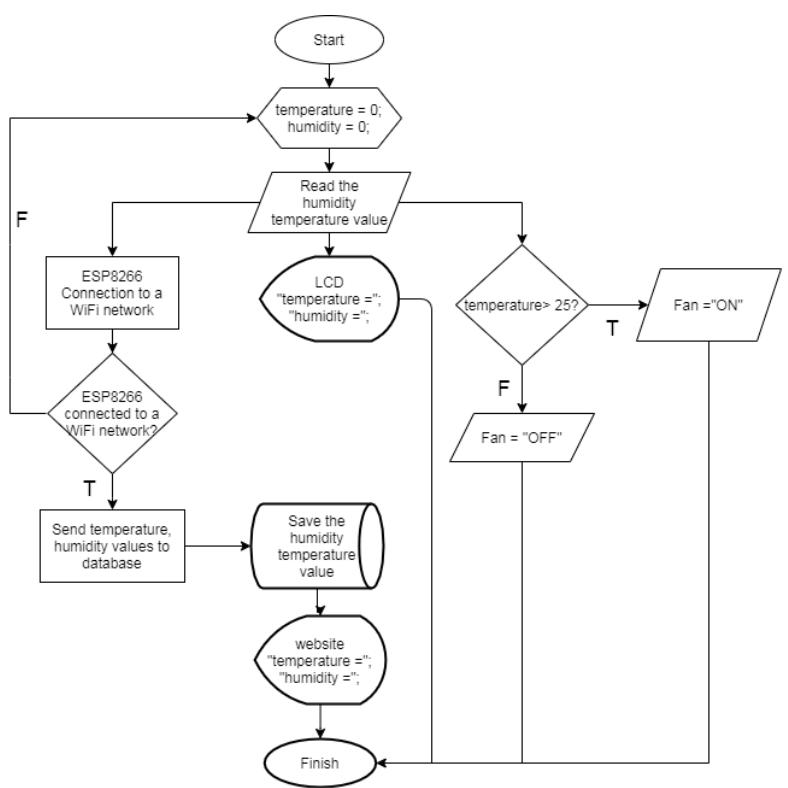

Picture 8. System Flowchart

\section{RESULTS AND DISCUSSION}

\section{A. Tool Making}

The hardware or hardware in Picture 9 used in temperature and humidity monitoring tools in chemical laboratories is the DHT11 sensor which is a temperature and humidity sensor, NodeMCU ESP8266 which is a microcontroller that will process DHT11 sensor data so that it becomes output or output data, fan fans, relay, breadboard, LCD, and jumper cables. A series of temperature and humidity monitoring tools can be seen in Picture 1 (Wijanarko, 2017).

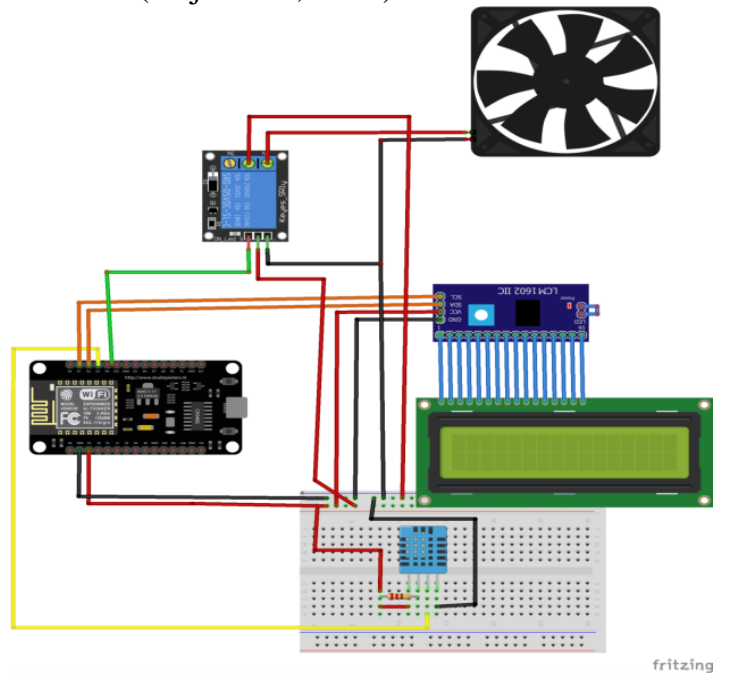

Picture 9. Series of Temperature and Humidity Monitoring Equipment

\section{B. Database Creation}

The database used is SQLyog Enterprise. Database created using tables that have been adapted to the needs of temperature and humidity monitoring tools in chemical laboratories. This database file is used to store data and information on the results of temperature and humidity measurements in chemical laboratories. There are 2 tables in the database, an admin table and a monitoring table.

Table 1. Admin table

\begin{tabular}{|c|c|l|}
\hline Field Name & Data Type & \multicolumn{1}{|c|}{ Information } \\
\hline Username & Varchar & $\begin{array}{l}\text { Username from } \\
\text { the user used } \\
\text { when logging in to } \\
\text { the website. }\end{array}$ \\
\hline Password & Varchar & $\begin{array}{l}\text { User password } \\
\text { used when logging } \\
\text { in to the website. }\end{array}$ \\
\hline Name & Varchar & User's full name. \\
\hline Nip & Varchar & $\begin{array}{l}\text { User Identification } \\
\text { Number of the } \\
\text { user. }\end{array}$ \\
\hline Date of birth & Date & $\begin{array}{l}\text { User's date of } \\
\text { birth. }\end{array}$ \\
\hline
\end{tabular}

Table 2. Monitoring table

\begin{tabular}{|l|l|l|}
\hline Field Name & \multicolumn{1}{|c|}{ Data Type } & \multicolumn{1}{|c|}{ Information } \\
\hline Id & BigInt & $\begin{array}{l}\text { Temperature and } \\
\text { humidity sequence } \\
\text { numbers. }\end{array}$ \\
\hline hemperature & Float & $\begin{array}{l}\text { Temperature data } \\
\text { obtained from the } \\
\text { measurement results } \\
\text { of the DHT11 sensor. }\end{array}$ \\
\hline date time & Int & $\begin{array}{l}\text { Humidity data } \\
\text { obtained from the } \\
\text { measurement results } \\
\text { of the DHT11 sensor. }\end{array}$ \\
\hline
\end{tabular}

\section{RESULTS AND DISCUSSION}

\section{Tool Making}

The hardware or hardware in Picture 9 used in temperature and humidity monitoring tools in chemical laboratories is the DHT11 sensor which is a temperature and humidity sensor, NodeMCU ESP8266 which is a microcontroller that will process DHT11 sensor data so that it becomes output or output data, fan fans, relay, breadboard, LCD, and jumper cables. A series of temperature and humidity monitoring tools can be seen in Picture 1 (Wijanarko, 2017). 


\section{Website making}

There are several pages that will be created on the temperature and humidity monitoring website in this chemical laboratory.

1. Display Login Page

In Picture 10, a website login page displays by entering the username and password of the user or operator, so you will be able to access the temperature and humidity monitoring website at the chemical laboratory.

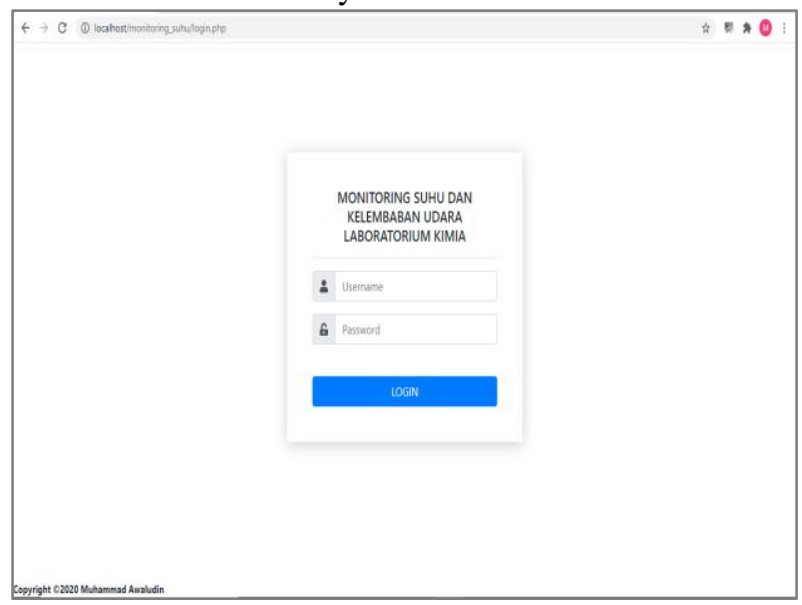

Picture 10. The Login Page Display

\section{Home Page Display}

Picture 11, is the initial display when login is successful, where on this page there is the latest temperature and humidity data stored in the database.

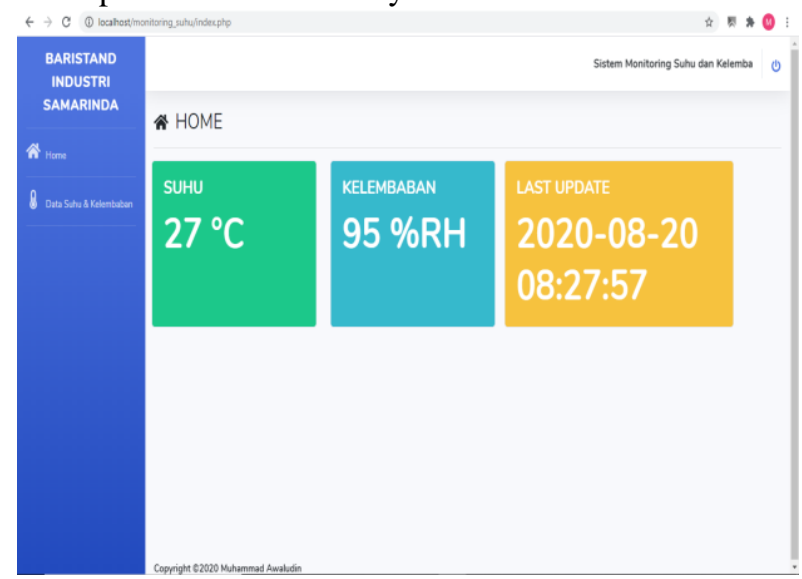

Picture 11. Home page display

3. Display of Temperature and Humidity Data Page Picture 12 is a detailed page display of the temperature and humidity data history based on the last 50 data displayed in detail where the data is data stored in the database.

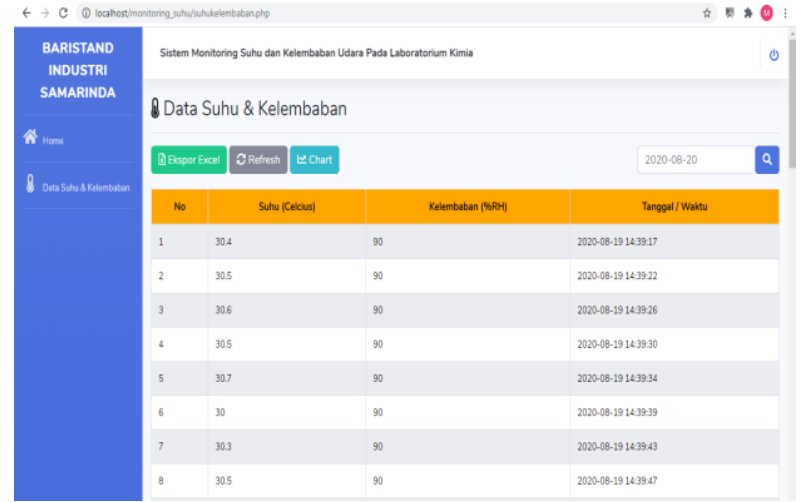

Picture 12. Display of Air Temperature and Humidity Data Page

4. Chart Page Views

Pictures 13 and 14 are a page display of a chart or graph of air temperature and humidity in a chemical laboratory based on the last 50 data.

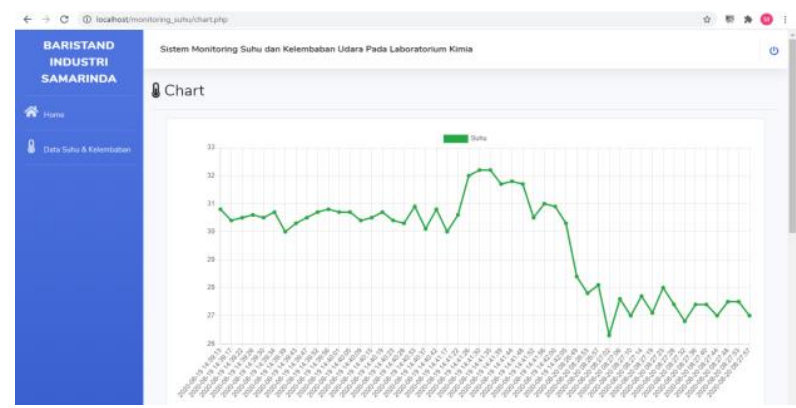

Picture 13.Graphic Page Display (Temperature)

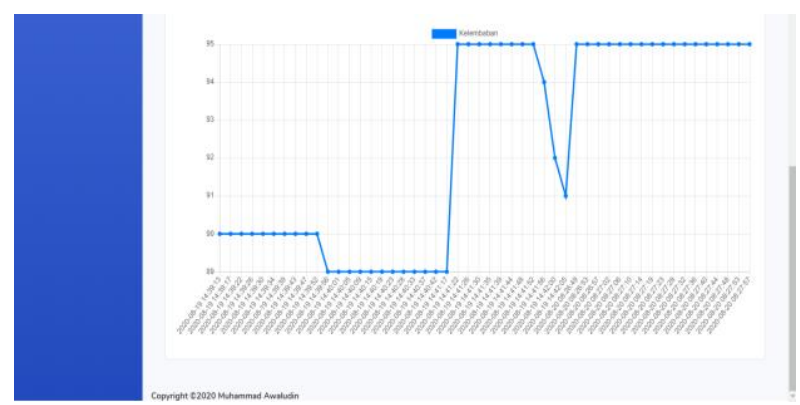

Picture 14. Graph Page View (Humidity)

\section{Hardware Testing}

1. DHT Sensor Test11

Testing the temperature and humidity sensors using DHT11 aims to determine the accuracy of the DHT11 sensor air temperature and humidity readings.

Table 3.Temperature test results on the DHT11 sensor and thermometer

\begin{tabular}{|c|c|c|c|}
\hline No. & $\begin{array}{c}\text { DHT11 } \\
\text { (Temperature) }\end{array}$ & Thermometer & $\begin{array}{c}\text { Error }\left(^{\circ}\right. \\
\text { C) }\end{array}$ \\
\hline 1. & 24.0 & 25.0 & 1 \\
\hline 2. & 24.9 & 26.0 & 1,1 \\
\hline 3 & 25.2 & 25.5 & 0.3 \\
\hline 4. & 25.4 & 25.9 & 0.5 \\
\hline 5. & 25.7 & 25.9 & 0.2 \\
\hline
\end{tabular}


Table 4. Humidity test results on the DHT11 and Hygrometer sensors

\begin{tabular}{|c|c|c|c|}
\hline No. & $\begin{array}{c}\text { DHT11 } \\
\text { (Humidity) }\end{array}$ & Hygrometer & $\begin{array}{c}\text { Error } \\
(\% \text { RH) }\end{array}$ \\
\hline 1. & 51 & 53 & 2 \\
\hline 2. & 51 & 55 & 4 \\
\hline 3 & 55 & 58 & 3 \\
\hline 4. & 62 & 63 & 1 \\
\hline 5. & 63 & 63 & 0 \\
\hline
\end{tabular}

\section{Fan Testing (Cooling)}

The fan test (cooler) in Table 5 aims to determine whether the fan works in accordance with what has been programmed previously.

Table 5.The fan test results (cooler)

\begin{tabular}{|c|c|c|}
\hline No. & $\begin{array}{c}\text { DHT11 } \\
\text { (Temperature) }\end{array}$ & Fan \\
\hline 1. & 24.0 & OFF \\
\hline 2. & 24.8 & OFF \\
\hline 3 & 25 & OFF \\
\hline 4. & 25.9 & ON \\
\hline 5. & 26.2 & ON \\
\hline
\end{tabular}

From the data obtained from the table above, the results of temperature measurements exceed 25degrees Celsius will make the conditions on the fan turn on. If the temperature measurement is less than or equal to 25 degrees Celsius, the fan will die.

\section{16x2 LCD testing}

The function of the LCD program in Picture 15 shows the results of temperature and humidity measurements obtained from the DHT11 sensor readings that have been processed by the NodeMCU
ESP8266 microcontroller. The test here is carried out when the system is turned on, the LCD will turn on by displaying temperature and humidity information in the chemical laboratory.

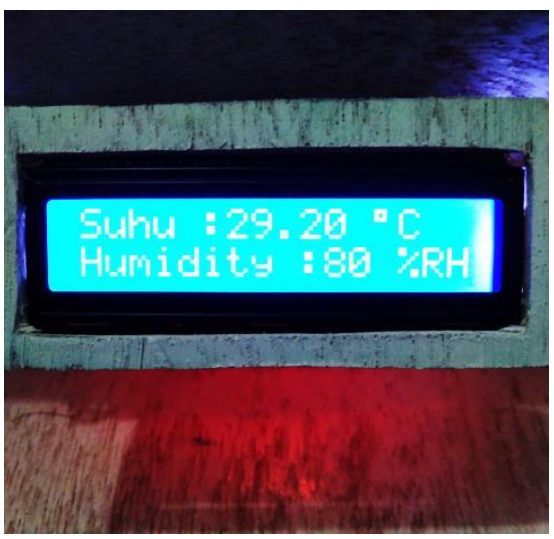

Picture 15. LCD Testing

When testing the LCD, the temperature and humidity values read by the DHT11 sensor in the chemical laboratory will appear so that if there is no internet connection which makes monitoring via the website impossible, monitoring can still be done via the LCD.

\section{E. White-Box Testing}

Testing on temperature and humidity monitoring tools in the chemical laboratory in Table 6 includes several modules. Testing includes program listings, types of tests, expected results, and test results.

Table 6. White Box Testing

\begin{tabular}{|c|c|c|c|}
\hline \# & Description & Program Code & Information \\
\hline 1. & $\begin{array}{l}\text { Connect NodeMCU } \\
\text { ESP8266 to a WIFI } \\
\text { network }\end{array}$ & $\begin{array}{l}\text { // include the ESP8266 library } \\
\text { \#include <ESP8266HTTPClient.h> } \\
\text { \#include <ESP8266WiFi.h> } \\
\text { / network settings } \\
\text { const char * ssid = "WELLND"; } \\
\text { const char * password = "wel12345"; } \\
\text { const char * host = "192.168.43.28"; // } \\
\text { wifi connection settings } \\
\text { WiFi.hostname ("InternetofThings"); } \\
\text { WiFi.begin (ssid, password); } \\
\text { // if successfully connected } \\
\text { // show message on serial Wifi connected } \\
\text { Serial.println ("WiFi Connected"); } \\
\text { // check wifi connection } \\
\text { if (WiFi.status ()! = WL_ConNECTED) } \\
\text { \{ / nodemcukeeps trying connections } \\
\text { Serial. Print ("."); } \\
\text { delay (2000); } \\
\text { \} }\end{array}$ & $\begin{array}{l}\text { Successfully connected } \\
\text { to the web server }\end{array}$ \\
\hline 2. & $\begin{array}{l}\text { Reads air temperature } \\
\text { and humidity on the } \\
\text { DHT11 sensor }\end{array}$ & $\begin{array}{l}\text { // include DHT11 temperature and humidity } \\
\text { sensor library } \\
\text { \#include <DHT.h> } \\
\text { \#define DHT_PIN 0 // DHT11 pin D2 } \\
\text { \#define DHTTYPE DHT11 } \\
\text { // create variables for the DHT sensor } \\
\text { DHT dht (DHT_PIN, DHTTYPE); } \\
\text { // variables to accommodate the values of } \\
\text { temperature and humidity }\end{array}$ & $\begin{array}{l}\text { Successfully read data } \\
\text { from DHT11 sensor and } \\
\text { display on serial } \\
\text { monitor }\end{array}$ \\
\hline
\end{tabular}




\begin{tabular}{|c|c|c|c|}
\hline & & $\begin{array}{l}\text { float temperature; } \\
\text { humidity; } \\
\text { void setup () } \\
\text { dht.begin (); } \\
\text { void loop () \{ } \\
\text { // read the values for humidity and } \\
\text { temperature } \\
\text { humidity = dht.readHumidity (); } \\
\text { temperature = dht.readTemperature (); } \\
\text { // show on Serial Monitor } \\
\text { Serial.println ("Temperature:" + String } \\
\text { (temperature)); } \\
\text { Serial.println ("Humidity:" + String } \\
\text { (humidity)); } \\
\text { Serial.println (WiFi.localIP ()); } \\
\text { Serial.println (); }\end{array}$ & \\
\hline 3. & Output on the LCD & $\begin{array}{l}\text { // include LCD I2C library } \\
\text { \#include <Wire.h> } \\
\text { \#include <LiquidCrystal_I2C.h> } \\
\text { // ConPicture the I2C address and the } \\
\text { number of columns and rows } \\
\text { LiquidCrystal_I2C lcd (0x27, 16, 2); } \\
\text { // display on the LCD } \\
\text { lcd.clear (); } \\
\text { lcd.setCursor (0,0); } \\
\text { lcd.print ("Temperature:" + String } \\
\text { (temperature)); } \\
\text { lcd.print (""); } \\
\text { lcd.write (degree_ symbol); } \\
\text { lcd.print ("C"); } \\
\text { lcd.setCursor (0,1); } \\
\text { lcd.print ("Humidity:" + String } \\
\text { (humidity)); } \\
\text { lcd.print ("o RH"); }\end{array}$ & $\begin{array}{l}\text { Successfully displays } \\
\text { the measurement results } \\
\text { of the DHT11 sensor on } \\
\text { the LCD }\end{array}$ \\
\hline 4. & Send data to server & $\begin{array}{l}\text { // check the connection to the server } \\
\text { WifiClient client; } \\
\text { if (! client.connect (host, 80)) } \\
\text { \{ } \\
\text { Serial.println ("Connection Failed"); } \\
\text { return; } \\
\text { \} } \\
\text { // the process of sending data to the } \\
\text { server } \\
\text { String Link; } \\
\text { HTTPClient http; } \\
\text { Link = "http: //" + String (host) + } \\
\text { "/monitoring_suhu/kirimdata.php?temp=" + } \\
\text { String (temperature) + "\& humidity =" + } \\
\text { String (humidity); } \\
\text { // link execution } \\
\text { http.begin (Link); } \\
\text { // GET mode } \\
\text { http.GET (); } \\
\text { http.end (); } \\
\text { delay (4000); }\end{array}$ & $\begin{array}{l}\text { Successfully sent data } \\
\text { to the server and stored } \\
\text { in the database }\end{array}$ \\
\hline 5. & Fan and Relay Module & $\begin{array}{l}\text { \#define RELAY } 2 \text { // Relay pin D4 } \\
\text { pinMode (RELAY, OUTPUT); } \\
\text { digitalWrite (RELAY, HIGH); } \\
\text { // the condition of the fan turns on when } \\
\text { the room temperature is above } 25 \text { degrees } \\
\text { Celsius } \\
\text { if (temperature> 25) ( } \\
\text { digital Write (RELAY, LOW); } \\
\text { \} else \{ } \\
\text { digitalWrite (RELAY, HIGH); } \\
\text { \} }\end{array}$ & $\begin{array}{l}\text { Successfully turn on the } \\
\text { fan when the } \\
\text { temperature is over } 25 \\
\text { degrees Celsius and the } \\
\text { fan turns off when the } \\
\text { temperature is less than } \\
25 \text { degrees Celsius }\end{array}$ \\
\hline
\end{tabular}




\section{CONCLUSION}

To make a temperature and humidity monitoring tool in a chemical laboratory based on the Internet of Things (IoT), the main components are needed, namely, NodeMCU ESP8266 as a microcontroller that processes data to produce output, DHT11 sensor as temperature and humidity input, $16 \times 2$ LCD as output display. , relay as a switch that connects the fan, fan as hardware for air conditioning, php myadmin as database manager, and XAMPP as local host.

The temperature and humidity monitoring tool in a chemical laboratory that is made has an air conditioning control system so that when the room temperature exceeds a predetermined limit the fan will turn on.

By implementing the Internet of Things (IoT) on the device so that it can monitor temperature and humidity through the internet by accessing a website that has been created, it can be accessed anywhere and anytime.

Based on the results of the tests that have been carried out, it can be concluded that the temperature and humidity monitoring tool can function properly, where each tool can function properly.

\section{REFERENCES}

Amanah, I., 2011. Hazard Identification and Risk Assessment in the Laboratory, Journal of the Faculty of Engineering, Diponegoro University. Aviana, PS, 2012. Implementation of Internal Control in Computer-Based Accounting Information Systems, Scientific Journal of Accounting. Vol. 1 (4). 65-70

Apriliya, K., 2016. Temperature and Humidity Monitoring System for Egg Incubator Through Global System For Mobile Network Based on Short Message Service. Research. Lampung: University of Lampung.

Ekojono, P., Cahya. R., Anugrah, NR, 2018. Spreadsheet Programming for Electronic Circuit Control Modeling. Malang: POLINEMA PRESS.

Gaol, LJ 2013. Management Information Systems Understanding and Applications. Jakarta: PT Grasindo.

Gunawan D, S., Wahyuono S, Donatus IA, Purnomo. 2011. Weather: Research Results, Properties, and Usage. Yogyakarta: PPOT UGM.

Hardyanto, RH 2017. Concept of the Internet of Things in Web-Based Learning, Journal of Informatics Dynamics. Vol. 6 (1). 87-97

Hidayati, P. 2011. The Effect of Temperature Settings on AC Split Performance, Journal of Energy Conversion Engineering.

Irfan. 2016. Computer Laboratory Temperature Monitoring System Using Arduino-Based
SMS. Essay. Samarinda: STMIK Widya Cipta Dharma Samarinda.

Lagiyono. 2012. Effect of Air Intake on Temperature of Air Conditioner (AC) 1 pk Capacity in the Test Installation Room, Journal of the Faculty of Engineering, State University of Semarang.

Prasetyo, A. 2018. Definition of resistors, types of resistors, and resistor functions. (https://www.kompasiana.com/spampam/5b86b 6e46ddcae2040310973/resistor-pengentukresistor-jenis-jenis-resistor-da-fungsi-resistor, accessed March 27, 2020)

Pressman, RS 2012. Software Engineering Practitioner Approach 7. Yogyakartan: ANDI.

Saputro, TT 2017. NodeMCU Tutorial First Meeting, (https://embeddednesia.com/v1/tutorialnodemcu-pertidang-pertama/, accessed 27 March 2020)

Sunardi and Siti Z. 2013. Physics for SMA / MA Class $\mathrm{X}$ Specialization. Bandung: YramaWidya.

Susanto, Azhar. 2013. Management Information Systems. Bandung: Lingga Jaya.

Sutabri, T. 2012. Concept of Information Systems. Yogyakarta: CV Andi Offset.

Wijanarko, D. 2017. Monitoring of Temperature and Humidity Using SMS Gateway in the Automatic Microcontroller-Based Tempe Fermentation Process. Essay. Jember: Jember State Polytechnic. 